\title{
INVENÇÕES E PRÁTICAS EM TREINAMENTO COLABORTIVO ${ }^{1}$
}

\section{INVENTIONS AND PRACTICES IN COLLABORTIVE TRAINING}

\author{
Jairit Garavit ${ }^{2}$ \\ https://orcid.org/0000-0003-1976-9891
}

1. ¿Este produto é o resultado do trabalho árduo de uma de suas Linhas de Pesquisa do projeto "Como deve pesquisar em Educação virtual e a distância?" do ano de 2021, realizada com Membros de forma interdisciplinar e interinstitucional (Professores - Alunos) da Pesquisa Seedbed: Sistemas Integrados de Gestão "Integradoss" Anexados ao GrupLAC: SIGCIENTY da Universidade Nacional Aberta e a Distância UNAD.

2. Engenheiro Industrial, Especialista em Educação Superior e à Distância, Mestre em Sistemas Integrados de Gestão HSEQ-RSC, Revisor de Pares da Elsevier, Revisor de Pares da Publons Academy e Advisor \& Peer Rewiever de Mendeley, Editor de Currículo em Revistas Acadêmicas - Minciencias. Líder da Seedbed de Pesquisa "Integradoss" e nomeado Professor Pesquisador da Escola de Ciências Básicas, Tecnologias e Engenharia ECBTI. Zona Caribenha, na Universidade Nacional Aberta e a Distância - UNAD. Email institucional Jairit.Garavit@unad.edu.co

Projeto de Pesquisa: ¿Cómo pesquisar em Educação virtual e a distância? 
Resumo: Alguns dos objetivos mais difíceis do ensino superior são o avanço do pensamento crítico ou do treinamento atual e profundo (em oposição ao treinamento trivial), promovendo a apreciação e aprovação de nossos semelhantes e aumentando a criação interpessoal (com reforços nas habilidades da equipe). Neste capítulo, examinamos a abordagem de treinamento colaborativo, que é especialmente projetada com objetivos bem fundamentados em mente. O treinamento colaborativo requer que pequenos grupos trabalhem em tarefas específicas. Seu objetivo é eliminar as fragilidades da abordagem tradicional de pequenos grupos por meio de uma estruturação cuidadosa de atividades, encontrando a chave para o sucesso na formação colaborativa. Contudo, O princípio fundamental de projetar ambientes educacionais com uma abordagem centrada no aluno é amplamente aceito. Uma vez que existem diferenças significativas em comparação com os designs tradicionais em termos de papéis do professor e do aluno. É necessário interpretar as qualidades do aluno que deve participar ativamente do treinamento, analisar muito bem a natureza da aprendizagem e projetar o ambiente de treinamento colaborativo adequado.

Palavras chaves: Treinamento Colaborativo, Ambientes Educacionais, Abordagens Educacionais, Processos Educacionais Tradicionais.

Abstract: Some of the most difficult goals of higher education are the advancement of critical thought or current and deep training (in opposition to trivial training), fostering the appreciation and approval of our fellow men, and increasing interpersonal creation (with reinforcements in team skills). This chapter examines the collaborative training approach, which is specially designed with well-founded objectives in mind. Collaborative training requires small groups to work on specific tasks. Its objective is to eliminate the weaknesses of the traditional small group approach through a careful structuring of activities, finding the key to success in collaborative formation. However, the fundamental principle of designing educational environments with a student-centered approach is widely accepted. Since there are significant differences compared to traditional designs in terms of teacher and student roles. It is necessary to interpret the qualities of the student who must actively participate in the training, analyze the nature of learning very well and design the appropriate collaborative training environment.

Keywords: Collaborative Training, Educational Environments, Educational Approaches, Traditional educational processes.

\section{Introdução}

O objetivo do treinamento em estágio pequeno é que os alunos possam trabalhar juntos para melhorar seu aprendizado, tanto em grupos quanto individualmente. A chave para o treinamento colaborativo é a estruturação cuidadosa de grupos de aprendizagem. Existem muitas maneiras de estruturar esses grupos, mas alguns dos elementos-chave são construir interdependência, projetar processos interativos e responsabilidade. Além disso, o desenvolvimento de habilidades sociais em 
áreas como tomada de decisão, comunicação e resolução de conflitos também são elementos essenciais do treinamento colaborativo. No entanto, existe uma perspectiva internacional sobre o treinamento colaborativo que, ao enfatizar as práticas e alguns de seus efeitos;

Durante o treinamento colaborativo, os alunos veem outras perspectivas e alternativas; Eles compartilham suas ideias, criticam e fornecem feedback, sendo o feedback útil para aumentar a consciência dos alunos sobre seus objetivos de aprendizagem e as estratégias que usarão para atingir esses objetivos. A colaboração fornece a base para o apoio mútuo e permite que os alunos aprendam uns com os outros. Embora a interação primária seja a interação aluno-aluno, em vez da interação professor-aluno, ainda há um papel de ensino nesta abordagem. A maioria dos especialistas concorda que a base do treinamento colaborativo é baseada em várias proposições importantes.

\section{Propostas de treinamento colaborativo}

A primeira proposta, que está na base da formação colaborativa, é respeitar os alunos independentemente de sua origem étnica, mental, educacional ou social e acreditar em seu potencial de sucesso acadêmico. Sapon-Shevin, Ayres e Duncan (1994). O treinamento colaborativo é baseado na diversidade, molda e promove o apoio e o vínculo entre os pares. Todos os alunos precisam aprender e trabalhar em ambientes que atendam às suas necessidades individuais e reconheçam seus pontos fortes individuais. Todos os alunos devem aprender em uma comunidade de apoio, onde se sintam seguros para assumir compromissos.

A segunda proposição subjacente ao treinamento colaborativo é que a aprendizagem deve promover um senso de comunidade compartilhada. Aprender, como viver, é um fenômeno natural e social. Essa abordagem fornece aos alunos apoio e incentivo por meio de interações sistemáticas em sala de aula. A sinergia mental se desenvolve e relacionamentos positivos são formados naturalmente.

Terceiro, a aprendizagem cooperativa é baseada na indicação de que o treinamento é um processo ativo e construtivo. Myers e Jones (1993) Este tipo de treinamento aborda o conteúdo da lição por meio de exercícios de resolução de problemas, pequenos grupos informais, analogias, estudos de caso, dramatizações e outras atividades que requerem a aplicação do que foi aprendido aos alunos. Fale, ouça, leia, escreva e onde a oportunidade de interação se reflete. Como resultado, o aprendizado não é adquirido passivamente e os dados científicos não são simplesmente adicionados ao conhecimento existente. Os alunos muitas vezes assimilam novo material e pontos de vista conflitantes e combinam, reinterpretam e transformam novas informações até absorvê-las. Assim, a aprendizagem é criada, não imitada. 
O papel do professor muda de informador para facilitador da aprendizagem. Isso não significa que os professores, que sempre tiveram autoridade absoluta, delegarão suas responsabilidades aos seus alunos, mas sim que assumirão o papel de professores auxiliares, ajudando os alunos a gerar suas próprias ideias e a revelar e desenvolver o conhecimento tácito. (Belenky, Clinchy et al. Goldberger e Tarule, 1986).

\section{Hipóteses e pesquisas sobre abordagens educacionais}

Construir uma sala de aula colaborativa requer uma compreensão da teoria subjacente para que abordagens de ensino eficazes possam ser selecionadas. Leamnson (1999) enfatiza: Uma boa pedagogia é o que convém, se escolhe; não se limita a um método, por mais inovador ou popular que seja. Da mesma forma, Palmer (1996) nos lembra que o desafio que devemos superar não é reduzir o bom ensino a uma determinada forma, modelo, metodologia ou técnica, mas sim reduzir a dinâmica do bom ensino a níveis mais profundos, sua base e qualquer forma leva. É a compreensão da dinâmica que torna a conexão um elemento poderoso na aprendizagem.

Usar uma abordagem colaborativa e conectada também reforça os conceitos de aprendizado profundo. Quatro componentes principais, totalmente compatíveis com as práticas de treinamento colaborativo, caracterizam uma abordagem mais profunda do que superficial. Rhem (1995) resume esses componentes da seguinte forma:

- Argumento motivacional: O que aprendemos melhor é o que precisamos saber; a motivação intrínseca está inextricavelmente ligada aos níveis de escolha e controle; as lições que os destroem também destroem o senso de propriedade e, portanto, um dos elementos mais poderosos da aprendizagem ao longo da vida.

- Dinamismo dos alunos:Aprendizado profundo e "não" andam de mãos dadas. Fazer isso sozinho não é suficiente, a capacidade mental deve combinar conceitos abstratos com atividade para torná-los lógicos e significativos; o estado mental passivo, por outro lado, leva ao aprendizado superficial.

- Interações com terceiros: O professor não é a única fonte de ensino e inspiração, os colegas que trabalham em grupos alcançam dimensões de aprendizagem que palestras e leituras não podem proporcionar.

\section{Plataforma de premissas estruturadas:}

Isso não significa simplesmente apresentar novo material de forma organizada. Além disso, significa reformular e se envolver com os conceitos que os alunos trazem com eles quando se inscrevem no curso. Abordagens profundas e aprendizagem abrangente são processos integrados. Quanto mais conceitos novos puderem ser associados aos costumes precursores dos alunos e ao 
conhecimento existente, mais os alunos ficarão impacientes com os dados estacionários e ansiosos para alcançar sua própria síntese.

A aprendizagem profunda e colaborativa se mistura perfeitamente quando os professores aproveitam as teorias subjacentes à aprendizagem, fornecendo, além de outros métodos, a tarefa de motivar os alunos a envolver os alunos na base de conhecimento. Os alunos geralmente ficam motivados quando o material do curso é relevante para suas próprias vidas e aprendizado. Se os alunos puderem colocar as informações no conteúdo em seu próprio contexto pessoal, essas informações serão permanentes e acessíveis conforme necessário (o efeito de autodireção). Essas investigações são baseadas em Jensen (2000) descobrindo as próprias conexões dos alunos ao invés de impor suas próprias conexões e encorajar os alunos a usar seu próprio vocabulário para aprendizagem posterior.

Essa recomendação torna as tarefas fora da classe muito importantes. Normalmente, os professores simplesmente coletam e classificam as tarefas; eles enviam a mensagem aos alunos de que o dever de casa é apenas um exercício artificial a ser avaliado por um especialista chato (professor). Para evitar essa percepção e permitir que os alunos aprendam de forma interativa e ativa com seus colegas dentro de modelos de aprendizagem colaborativa e profunda, os professores devem considerar avaliações de pares ou outros usos significativos do dever de casa fora da classe. Como os alunos preparam as tarefas individualmente fora da classe, as atividades em grupo baseadas nessas preparações devem resultar em um aprendizado profundo.

O uso colaborativo de atribuições também se baseia no que sabemos sobre o desenvolvimento cognitivo. (Leamnson (1999) A aprendizagem pode ser definida como a fixação de resumos específicos apropriados e desejados no cérebro por meio do uso repetido. Os professores fortalecem seus próprios nervos cerebrais enquanto se preparam para as aulas, mas o verdadeiro teste do treinamento é como eles os afetam. dos alunos.

Quando um professor combina conscientemente uma tarefa bem planejada com atividades colaborativas em sala de aula e feedback, que é o seu propósito, a repetição necessária para a aprendizagem do aluno é alcançada abordando o mesmo tópico de ângulos diferentes, em vez de memorizá-lo. Bransford, Brown e Culinária (2000) Os alunos aprendem o quê, quanto, quando, eles precisam de feedback sobre onde sabem e como usarão as informações que aprenderam. $\mathrm{O}$ valor da repetição torna-se evidente quando o treinamento colaborativo é adicionado ao aprendizado da escrita, um exemplo de atividade extraclasse, como um diário de dupla entrada.

Com um diário de dupla faixa ou dupla entrada, os alunos identificam as principais ideias de um artigo, capítulo ou palestrante convidado, no lado esquerdo de uma planilha (Word cujo modelo é distribuído aos alunos ou enviado por e-mail). Diante do campo em que indicam as ideias principais, eles redigem seus comentários pessoais que relacionam a ideia principal com outro material acadêmico, atualidade ou experiências pessoais. (Ver tabela 1). Para evitar sobrecarregar 
os alunos, os professores podem limitar o número de ideias principais ou a duração da intervenção do diário de dupla entrada.

Em vez de colocar o diário em uma pasta para avaliação posterior, os professores em treinamento colaborativo podem formar pares de alunos; encorajando-os a discutir suas principais idéias e respostas uns com os outros. Este método de discussão em pares é baseado na premissa do pensamento crítico. Brookfield (1987) e outros enfatizam que o pensamento crítico se baseia na discussão por meio da identificação de suposições e, em última instância, da exploração e conceituação de alternativas.

\section{Tabela 1.}

\section{Jornal Acadêmico de Entrada Dupla}

\begin{tabular}{|c|c|}
\hline Ideias principais & Respostas \\
\hline $\begin{array}{l}\text { O pensamento criativo pode } \\
\text { assumir a forma de } \\
\text { pensamento crítico. }\end{array}$ & $\begin{array}{l}\text { Conforme entendido pela literatura acadêmica e discussões com } \\
\text { membros do corpo docente, pensamento crítico. } \\
\text { É um conceito difícil de especificar e ainda mais complicado de ensinar. } \\
\text { Acredito que o pensamento crítico pode ser ensinado "fazendo" algo em } \\
\text { um campo específico. Atividades como o Documento de Entrada Dupla } \\
\text { desenvolvem o pensamento crítico. } \\
\text { A criatividade é um conceito ainda mais difícil. Para mim, a criatividade } \\
\text { vem do "pensamento": a criatividade não pode ser separada da crítica. } \\
\text { Duvido que você entenda o ponto de "formabilidade" de Sternberg. }\end{array}$ \\
\hline $\begin{array}{l}\text { A teoria do investimento em } \\
\text { criatividade afirma que } \\
\text { pessoas com criatividade } \\
\text { superior têm as mesmas } \\
\text { características. }\end{array}$ & $\begin{array}{l}\text { Podemos encontrar pessoas talentosas e procurar essas características, ou } \\
\text { podemos encontrar pessoas com essas características comuns e então } \\
\text { explorar sua criatividade? }\end{array}$ \\
\hline
\end{tabular}

\section{Garavit, J. 2021.}

A combinação de trabalho externo com processamento em sala de aula resulta em uma repetição significativa para os alunos que provavelmente concluirão uma tarefa que sabem que compartilharão com seus colegas. Ler é a primeira exposição. Além disso, o diário manual, com as respostas pessoais dos alunos ao tópico, reintroduz o material para o aluno para a segunda revisão. As discussões em pares em sala de aula fornecem uma terceira iteração. (Os alunos que chegam sem fazer o dever de casa não serão pareados: eles se sentarão no final da aula e trabalharão em seu diário e anotações. É uma quarta iteração que eles terão que reconsiderar seu diário e anotações quando o professor fizer comentários:

Os professores que relutam em implementar o treinamento colaborativo podem ser persuadidos de que esse método resulta em aprendizagem concreta ao longo da vida, apoiada pela pesquisa. 
Tanto os resultados da aprendizagem quanto a dinâmica social do treinamento colaborativo foram estudados sob muitas condições. Slavin (1989-1990) considera esta orientação formativa um dos métodos de ensino mais abrangentes e meticulosamente pesquisados. Johnson, Johnson e Smith (1991) descrevem o número de estudos conduzidos nos últimos 90 anos como impressionante. As implicações autênticas do treinamento colaborativo no sucesso do aluno Além de seu efeito, os pesquisadores mencionados determinaram que este método de aprendizagem também afeta significativamente as relações interpessoais:

À medida que os relacionamentos dentro da sala de aula ou da universidade se tornam positivos, o absenteísmo diminui e o comprometimento dos alunos com o aprendizado, seu senso de responsabilidade pessoal por fazer o dever de casa designado, sua disposição para assumir tarefas difíceis, sua motivação, seu trabalho sem desistir, sua satisfação. moral, sua força para suportar as dificuldades e decepções para alcançá-la, seu desejo de defender suas universidades de críticas ou ataques de fora, seu entusiasmo para ouvir e ser influenciado por seus pares, seu compromisso com o sucesso e o desenvolvimento de seus pares, seu aumento de produtividade e sucesso.

De acordo com Cooper e Mueck (1990), as descobertas positivas mais consistentes sobre o treinamento colaborativo focam nas mudanças afetivas ou de atitude. Medidas de aquisição, como relações raciais / étnicas, diversidade de gênero, autoestima e outros benefícios sociais, são abordadas na pesquisa de treinamento colaborativo. Porque conhecer a teoria básica e a pesquisa por si só não resulta em uma sala de aula colaborativa que funcione bem: os professores devem saber como estabelecer e manter uma sala de aula para a aprendizagem colaborativa.

\section{Experiências em gerenciamento colaborativo de sala de aula}

Grande parte da literatura sobre a reforma do ensino superior é teórica e encorajadora. Use técnicas de aprendizagem ativa; Seja sensível na sala de aula; Promover o respeito pela diversidade; Desenvolva o pensamento crítico. Essas dificuldades costumam ser um fardo opressor para os professores. Como os professores e membros da escola responderão a esses desafios? Adicionar novos elementos aos cursos existentes sem um propósito, compromisso ou competência claros resultará em uma abordagem de contornar o problema tímida. Um aspecto importante do treinamento colaborativo é que ele fornece uma ferramenta prática para resolver esses desafios de uma forma pedagogicamente sólida e sistemática.

Ao configurar uma sala de aula colaborativa, os seguintes princípios-chave guiarão todas as decisões: 


\section{A interdependência real promove o comportamento colaborativo.}

Johnson, Johnson e Smith (1991) retratam o vício positivo em palavras semelhantes a estas: Cooperação resulta em esforços mutuamente benéficos dos participantes; portanto, todos os membros de um grupo; se benefician de los esfuerzos de los demás (Tu éxito me beneficiará a mí, mi éxito te beneficiará a ti), entienden que todos los integrantes del grupo cooperan un fin común (Nos hundiremos juntos o nos levantaremos juntos), saben que el el desempeño de uno depende mutuamente del desempeño del otro y de ellos mismos (No podemos hacer esto sin usted) y si un miembro del grupo es recompensado por su logro, y este se enorgullece del logro y lo celebra juntos (¡Obtuviste un 100 ! ¡Eso é genial!).

Em um ambiente educacional tradicional, os alunos tendem a trabalhar sozinhos ou competindo com outros. Em ambientes colaborativos e orientados para o grupo, todos os membros da classe, especialmente as equipes de membros do corpo docente, contribuem para os processos de aprendizagem uns dos outros. Por meio de um planejamento cuidadoso, os alunos constroem um envolvimento positivo que atinge:

- Objetivos comuns, como chegar a um consenso sobre soluções específicas para problemas ou alcançar uma solução em equipe.

- Recompensas conjuntas, como notas atribuídas individualmente que contam para a nota final referenciada pelos critérios, que são úteis ao invés de obstrutivas.

- Tarefas estruturadas, como um relatório ou um problema complexo, cujos capítulos são desenvolvidos com a entrada de membros do grupo.

- Líderes de discussão dos membros do grupo.

\section{O compromisso individual cria uma avaliação justa}

Embora recebam apoio mútuo, treinamento e incentivo, os alunos devem ser considerados individualmente responsáveis por seu próprio sucesso acadêmico. Como os alunos estão acostumados a ambientes acadêmicos nos quais competem com seus pares, este elemento de formação colaborativa deve ser assegurado: as notas finais devem ser baseadas no esforço pessoal, não podem ser confundidas ou compensadas pelas realizações dos outros. Os professores devem avaliar testes, projetos e exames finais como se estivessem em uma sala de aula onde o trabalho em grupo não é uma prática normal.

O engajamento positivo e a responsabilidade individual podem ser estabelecidos por meio de atividades cuidadosamente planejadas em sala de aula. Por exemplo, quando os alunos recebem planilhas ou estudos de caso para completarem juntos, os professores podem dizer que um dos membros do grupo de trabalho, escolhido aleatoriamente pelo professor durante a aula, será responsável por relatar o trabalho do grupo. É uma estrutura colaborativa chamada cabeças 
numeradas juntas. (Kagan, 1989), lição de resolução de problemas (Johnson, Johnson e Smith, 1991) ou solução estruturada de problemas. (Millis e Cottell, 1991). Essa abordagem produz muitos resultados positivos:

- Incentive todos os alunos do grupo a aprenderem o material do curso, pois eles não sabem qual professor será chamado para a aula.

- Incentive os alunos mais fracos a procurarem treinadores de pares.

- Incentive os alunos tímidos e menos habilidosos a serem porta-vozes do grupo, pois sua seleção como porta-vozes é aleatória e seu relato não é deles, mas de todo o grupo.

\section{Um método de avaliação direto, não competitivo e baseado em critérios promove a colaboração.}

O sistema de classificação aplicado pode afetar o engajamento positivo e a responsabilidade individual. Nada menos do que um sistema de notas no qual os alunos competem entre si pelas notas A e B pode reduzir a eficácia de uma sala de aula colaborativa. Em vez disso, um sistema de notas baseado em critérios permite que todos os alunos obtenham notas adequadas. Os padrões devem ser altos, mas as notas devem, em teoria, estar disponíveis para todos os alunos que trabalham em colaboração para atingir um padrão estabelecido.

Outro problema de qualificação diz respeito à qualificação dos projetos da equipe. Classificação de grupo indiferenciada para um único projeto, especialmente quando a maior parte do trabalho é feito fora da sala de aula. Nesse caso, isso levanta questões de desigualdade, e até mesmo questões éticas ou legais, e destrói a responsabilidade individual. Freqüentemente, um dos membros do grupo conclui a maior parte do trabalho. Este aluno gosta principalmente do poder dessa função, mas fica desconfortável quando outros alunos de seu grupo obtêm a mesma nota.

Os alunos que pouco contribuem para o trabalho entendem a mensagem de que seus esforços não são valorizados ou desejados e tiram uma conclusão negativa do trabalho: podem receber uma nota não merecida. Por esse motivo, é extremamente importante garantir a responsabilização por meio de colegas responsáveis e autoavaliação e que todos os alunos sejam pontuados de acordo com suas contribuições.

Alguns membros do corpo docente, especialmente em áreas de carreira, acham que situações em que o desempenho ou a falta de desempenho de um membro da equipe retarda o sucesso da equipe como um todo prepara os alunos para a vida real. Na realidade, Nenhum líder experiente da empresa permitiria que a equipe se dividisse em disputas ou comportamento excludente conforme o prazo para um trabalho ou contrato se aproximasse. Da mesma forma, nenhum supervisor responsável atribui a mesma classificação de desempenho a todos os seus funcionários. 


\section{Quem deve monitorar os procedimentos do grupo?}

Comportamentos como ouvir e dar feedback construtivo, bem como orientação em grupo de habilidades sociais, muitas vezes distinguem o treinamento colaborativo de formas menos estruturadas de trabalho em grupo. Essas práticas proativas permitem que os alunos reflitam sobre seus próprios métodos de aprendizagem e realizações. O processo grupal inclui a avaliação de competências como liderança, decisões tomadas, comunicação e resolução de conflitos. O processo não envolve apenas conteúdo; também cuida de como o grupo funciona. Depois de uma tarefa ou atividade, os alunos podem responder a perguntas como: Todos no grupo contribuíram? O que pode ser feito na atividade a seguir para melhorar o funcionamento do grupo? o Quais são as coisas mais importantes que você aprendeu hoje?

Os alunos podem não ser capazes de conectar as habilidades sociais com o aprendizado acadêmico no início, mas as habilidades sociais ainda são importantes. As habilidades interpessoais vão além da educação. Os alunos devem compreender o valor da interação colaborativa e respeito mútuo na vida adulta. Os professores devem modelar habilidades sociais apropriadas para os alunos, incluindo dar feedback construtivo ou obter respostas mais detalhadas por meio de perguntas de teste. Os professores devem reforçar essas habilidades sociais, discutindo explicitamente as maneiras pelas quais os alunos usam esses métodos de forma eficaz.

Em uma sala de aula colaborativa, o professor deve monitorar o comportamento do grupo e a aprendizagem movendo-se entre os grupos enquanto as equipes realizam tarefas comuns. Os professores se beneficiam de:

- Descubra o que os alunos realmente sabem ou quando e por que estão tendo dificuldades.

- Por serem próximos dos alunos, eles os incentivam a se concentrar nos deveres de casa.

- Envolva-se com os alunos, demonstrando interesse genuíno em seu desenvolvimento.

- Ao criar uma percepção acessível, eles eliminam o medo dos alunos de fazer perguntas bobas em público.

- Eles aprendem novas maneiras de ensinar o material do curso ouvindo os alunos explicarem os conceitos em suas próprias palavras de uma forma que seus colegas possam entender.

- Por meio de minilulas, eles ganham oportunidades de combinar ideias, construir a autoestima do grupo e passar a mensagem de que a opinião dos alunos como um todo é valorizada.

\section{Em sala de aula, técnicas de avaliação e evolução do aluno.}

O monitoramento dos alunos também pode incluir exercícios escritos projetados para entender se os alunos estão realmente aprendendo o que os professores acreditam que eles estão ensinando. Angelo e Cross (1993) escreveram diferentes técnicas para avaliar a aprendizagem dos alunos. 
Muitos deles, como o One Minute Report ou o More Complex Point, podem ser brevemente implementados, analisados e descritos. As práticas de avaliação em sala de aula não apenas ajudam o professor a entender o quanto os alunos aprenderam, mas também permitem que os alunos acompanhem seu próprio progresso acadêmico. A maioria das atividades colaborativas, quando devidamente monitoradas, tem valor para avaliação.

Por exemplo, o Visible Quiz (Staley, 2003), quando administrado de forma colaborativa, pode ajudar alunos e professores a determinar quão bem o conteúdo e os conceitos são compreendidos. No questionário visível, os alunos discutem, em pares ou pequenos grupos, as respostas adequadas às perguntas do questionário, que geralmente são projetadas na parede. As respostas podem ser de múltipla escolha (A, B, C ou D) ou Verdadeiro (D) e Falso (Y).

Cada naipe possui um conjunto de cartas coloridas (por exemplo, uma carta laranja para todas as opções A ou uma carta azul para todas as opções Corretas). Com uma nota do professor, um aluno de cada equipe indica a seleção da equipe. Portanto, fica claro se toda a classe entendeu bem ou não a questão, de forma simples e rápida. Se a maioria dos alunos deu uma resposta incorreta, a matéria pode ser reapreciada com uma curta aula no momento mais oportuno. Os grupos também podem ser solicitados a explicar por que deram a resposta errada, revelando conceitos errôneos, perguntas mal estruturadas ou pouco claras no processo.

Ele também fornece feedback instantâneo para professores e alunos. Também por meio dessa técnica, o treinamento de pares é aprimorado à medida que as equipes discutem cada questão. Johnston e Cooper (1997) desenvolveram o método Escolha a resposta mais correta, que é outra variante do questionário visível. Até mesmo atividades de sala de aula simples, como o Exame Visível, precisam ser praticadas corretamente.

\section{Atividades colaborativas}

Quatro princípios fundamentais para criar e avaliar atividades colaborativas podem ajudar alunos e professores.

\section{A reflexão do professor sobre a atividade proposta deve responder às questões-chave}

Como regra geral, os professores devem fazer a si mesmos as seguintes perguntas: O que vou fazer? Por que eu vou fazer isso? Como esta atividade vai melhorar meus objetivos de aula? Como vou apresentar esta atividade aos meus alunos? Como faço para criar grupos? Como monitorarei o aprendizado e a interação do aluno? Como vou desenvolver uma interdependência positiva (objetivo, materiais de origem, métodos de avaliação, funções, etc.)? Como vou manter o senso de responsabilidade individual dos alunos? Como o aprendizado, as interações e o sucesso geral 
afetam a atividade dos alunos? Vou avaliar? Que problemas espero que surjam? Como pode ser visto, é necessário um planejamento cuidadoso das atividades em grupo, em relação aos objetivos da aula.

\section{Os alunos, 0 ambiente e o valor da atividade apresentada}

Muitos alunos virão para a sua aula com estilos de aprendizagem que tendem a funcionar de forma independente. Além do mais, eles podem ter se cansado do trabalho em grupo desajeitado de seu passado de estudante. Portanto, os alunos devem compreender que as interações em grupo são voltadas para os objetivos e conquistas desejáveis do curso, como a aquisição das habilidades de trabalho em equipe necessárias nos locais de trabalho de hoje.

\section{Ilustrações claras para trabalho em grupo}

O trabalho em grupo pode ser frustrante para alunos e professores se as diretrizes relevantes não forem claras. Os alunos podem duvidar das habilidades organizacionais do professor e desperdiçar o valioso tempo da aula decifrando instruções. Para tarefas complexas, os professores podem distribuir instruções escritas aos alunos ou ao grupo. Você pode refletir na tela as tarefas a serem realizadas e o que se espera ou escrever na lousa (algumas salas de aula virtuais têm lousa). Para atividades mais simples, um aluno ou toda a classe pode ser solicitado a repetir as instruções dadas para reforçá-las.

Instruções claras não apenas descrevem a tarefa desejada, mas também estabelecem o tempo alocado para essa tarefa. Se os alunos não conseguirem planejar seu tempo com antecedência, eles podem não ser capazes de usar esse tempo com sabedoria, mesmo para breves atividades em sala de aula. Como regra geral, em vez de gastar vinte minutos em uma atividade que a maioria dos grupos pode concluir em dez minutos, eles devem receber um período de tempo razoavelmente curto e, em seguida, estendê-lo, se necessário.

Estudos como Chickering e Gamson, 1987, Evidências de que o tempo ativo é uma presença e um mecanismo crítico para o sucesso do aluno. Para maximizar o tempo ativo na lição de casa, os professores podem adicionar uma atividade adicional às suas aulas para grupos que concluam a lição de casa mais cedo. Essa atividade adicional pode muitas vezes ser problemas mais difíceis de resolver ou problemas mais complexos de discutir.

\section{Avaliação da missão cumprida}

Como mencionado acima, os alunos podem relutar em trabalhar em grupos, a menos que entendam o valor do treinamento colaborativo. O professor deve evitar a aparência de brincar com os alunos, não dando as informações necessárias a um grupo ao abordar um problema difícil. 
Geralmente, quando todos os membros do grupo dizem que precisam de ajuda, é apropriado ajudar esse grupo. Uma tática melhor seria enviar um orientador estudantil de um grupo diferente.

Às vezes, o professor, como autoridade, pode resumir a lição, confirmando assim que a lição foi aprendida dentro dos grupos. Os relatos produzidos pelos grupos, principalmente aqueles que demoram a ser concluídos, dão aos alunos a sensação de terem cumprido a tarefa. Quando o tempo designado é curto, os relatores podem enviar o relatório do grupo para outros membros do grupo por e-mail ou postá-lo no site do curso.

Os relatórios por e-mail são ideais para resumos de conferências, por exemplo, uma atividade chamada mesa redonda. A mesa redonda é uma estrutura de treinamento colaborativa útil para brainstorming, revisão, suposições ou prática de uma habilidade específica. Este aplicativo usa uma única folha de papel e uma caneta para cada membro do grupo de trabalho de treinamento. Para responder a uma pergunta ou problema, os alunos do grupo se revezam dizendo suas ideias em voz alta e anotando-as no papel.

Os membros da equipe normalmente têm que dizer e escrever suas respostas um por um, sem pular a linha, mas se eles ainda não têm uma ideia ou precisam de tempo, podem dizer vá em frente para que o brainstorming não se torne um problema. quebra-cabeça do cérebro.

A mesa redonda é mais eficaz quando usada em um conjunto de atividades cuidadosamente sequenciado. O brainstorming pode ser usado para reforçar as ideias das leituras ou para preparar o terreno para as discussões na próxima lição. Por exemplo, os alunos podem ser solicitados a identificar as características de um líder eficaz ou as características do terrorismo antes que os tópicos sejam apresentados em sala de aula.

O confronto da lista elaborada pelos alunos com a lista elaborada pelos especialistas da disciplina despertará o interesse dos alunos. Múltiplas respostas irão encorajar a criatividade e o aprendizado profundo. Esta atividade cria um engajamento positivo entre os membros da equipe devido ao espaço de escrita compartilhado. Ainda mais importante,

\section{Eficácia do grupo ou equipe}

Os três princípios a seguir podem eliminar muitos dos elementos disfuncionais dos grupos e maximizar a coesão da equipe.

\section{Os grupos devem ter um pequeno número de alunos}

A maioria dos professores com experiência em trabalho em grupo atenta para o fato de que os grupos são compostos por três ou quatro alunos. Um grupo de quatro alunos é geralmente considerado ideal porque inclui um número suficiente de alunos com uma variedade de pontos de 
vista, experiências e estilos de aprendizagem para ajudar na resolução de problemas. Se um membro do grupo estiver faltando, o grupo pode funcionar sem problemas. Um grupo de quatro não é um grupo grande, mas os alunos podem se esconder neste grupo. Todos os membros do grupo devem compartilhar as atribuições de trabalho de maneira justa. A vantagem adicional de um grupo de quatro é que os alunos podem formar pares facilmente dentro do grupo.

\section{A heterogeneidade é funcional nos grupos}

Stein e Hurd (2000) em seus estudos foram capazes de concordar que as equipes deveriam ser heterogêneas, variando em termos de gênero, etnia e habilidades acadêmicas. No entanto, Felder e Brent (1994) dão o seguinte exemplo, mostrando que a heterogeneidade nas habilidades é necessária.

As desvantagens de um grupo apenas de alunos fracos são óbvias, mas é igualmente indesejável ter um grupo apenas de alunos bem-sucedidos. Primeiro, os grupos fortes têm uma vantagem injusta sobre os outros grupos da classe. Em segundo lugar, os membros da equipe tendem a dividir tarefas e comunicar-se casualmente entre si, ignorando assim a interação dinâmica que demonstraria os benefícios comprovados do treinamento colaborativo.

Por outro lado, em grupos de habilidades mistas, os alunos mais fracos se beneficiarão ao ver como os alunos trabalham melhor e lidam com problemas; Os alunos bem-sucedidos serão capazes de compreender o assunto de uma maneira mais profunda, ensinando-o a seus amigos fracos.

O agrupamento heterogêneo aumenta a probabilidade de conclusão bem-sucedida de tarefas acadêmicas. Também oferece aos alunos a oportunidade de trabalhar construtivamente com uma variedade de pessoas que trazem diferentes abordagens e pontos fortes para as tarefas acadêmicas. As interações positivas com uma variedade de pessoas preparam os alunos para a vida empresarial moderna e para a sociedade como um todo. Seria sensato explicar aos alunos por que o professor cria o grupo, em vez de escolher seus próprios parceiros de grupo. Os grupos cujos membros são determinados pelos alunos tendem a ser homogêneos, portanto, é menos provável que existam diferentes maneiras de pensar. Funções e expectativas podem ser mais fixas,

\section{Tempos de trabalho entre grupos.}

É perigoso presumir que os alunos trarão para os grupos colaborativos as habilidades que lhes permitirão funcionar com eficácia. Os grupos de aprendizagem contínua são obrigados a perseverar adjacentemente pelo período apropriado para passar pelos estágios de emergência, conflito, normalização, ação e dispersão descritos na literatura sobre dinâmica de grupo (Tuckman, 1965; Tuckman \& Jensen, 1977). Os alunos precisam de tempo para se conhecerem, identificarem os pontos fortes uns dos outros e aprenderem a apoiar e treinar uns aos outros. A maioria dos 
especialistas recomenda que os grupos permaneçam juntos durante um longo projeto ou uma série de atividades em andamento, geralmente cerca de meio período.

\section{Gestão de grupo de atividades}

Preocupados com a perda de tempo, os membros do corpo docente desejam formar grupos rapidamente e concluir o trabalho em grupo rapidamente. Portanto, os alunos que participam ruidosamente de atividades em grupo podem informar imediatamente seus professores quando recebem o sinal dado. entenda que eles precisam prestar atenção. Nas turmas pequenas, basta anunciar o fim do tempo. Em salas de aula maiores, uma dica visual como levantar a mão é necessária (também chamada de dica silenciosa, em que os alunos levantam as mãos, também interrompe a fala para criar um efeito dominó). A utilização do sinal de silêncio em combinação com um sinal de áudio ajuda a concluir a atividade do grupo e também a garantir que o tempo definido não seja ultrapassado.

Com o gerenciamento de sala de aula eficaz, muitas atividades colaborativas podem ser concluídas em apenas alguns minutos. Por exemplo, uma atividade "Pense em Dupla e Compartilhe" pede aos alunos que façam uma pergunta sobre a aula ou o que tenho ensinado nos últimos quinze minutos. Resuma os três pontos mais importantes que apresentei durante este tempo. Tempo limite de 30 segundos para que eles pensem independentemente sobre sua resposta a uma pergunta importante. (Para contribuir com a avaliação da turma, muitos professores dão aos alunos dois minutos para escreverem suas respostas em cartões de índice, permitindo-lhes lembrar ou revisar o tópico mais tarde.)

Os alunos então se agrupam para comparar suas respostas, ensaiar suas respostas e obter feedback sobre suas ideias. Na terceira fase, os alunos têm o direito de falar (compartilhar) suas respostas. Alunos introvertidos que tiveram tempo suficiente para refletir entre as mãos levantadas e pedir para falar; Haverá também alunos tímidos que receberão incentivo e alunos que processarão a questão em profundidade. O sinal silencioso ajudará os professores a superar esses estágios, ganhando experiência.

O tempo também pode ser economizado usando arquivos de equipe, mesmo em turmas pequenas, quando os alunos são divididos em grupos permanentes (um período) ou semipermanentes (geralmente meio período). No início de cada aula, um membro designado do grupo recebe do professor o arquivo da equipe contendo os relatórios a serem enviados ao professor ou todos os materiais relevantes do curso. Durante a aula, os alunos colocam todas as suas atividades escritas em sala de aula nesta pasta, incluindo suas atribuições e respostas de avaliações de classe, como os cartões de índice do aplicativo "Pense em Pares e Compartilhe" ou a planilha da Mesa Redonda. O determinado aluno entrega este arquivo ao professor no final da aula. 
Para definir tarefas e estabelecer funções rapidamente, é importante identificar equipes e membros da equipe rapidamente. Os alunos podem ser numerados em grupos (um, dois, três, quatro) ou em equipes e seus membros podem ser diferenciados por meio de cartas de baralho. $\mathrm{O}$ jogo de cartas permite que os professores se comuniquem facilmente com seus alunos sobre as tarefas do grupo (na ordem das cartas) e seu papel dentro desse grupo (pelas cores das cartas). Também permite ao professor acompanhar os alunos que usaram da palavra, por exemplo, "Valete de Ouros" ou "Dois de Espadas", marcando os alunos que usaram da palavra com a preocupação de garantir a igualdade.

Quando membros adicionais ingressam em grupos, o número de pessoas no grupo pode aumentar para cinco e, na ausência de um dos membros do grupo, curingas podem ser usados para o quinto membro que tomar o seu lugar. Em classes maiores, dois ou mais baralhos de cartas podem ser usados, como cartas vermelhas e azuis. Podem ser usados decks de cores diferentes para corresponder a arquivos de cores diferentes.

As funções atribuídas dentro dos grupos (líder do grupo, responsável pelo registro, repórter e acompanhamento do aluno) devem ser alternadas com frequência para criar um envolvimento positivo. Essa prática eliminará o domínio de um único aluno, um problema comum freqüentemente experimentado em trabalhos de grupo menos estruturados, e proporcionará a todos os alunos a oportunidade de experimentar uma variedade de habilidades sociais, de comunicação e de liderança.

Atividades de construção de equipe podem construir coesão da equipe, mas as atividades não devem ser frívolas e exercícios fora do conteúdo do curso. Atividades baseadas em conteúdo, como a entrevista tripla, incentivam os alunos a se concentrarem no material do curso enquanto se comunicam positivamente uns com os outros. Na atividade Entrevista Tripla, um aluno entrevista outro durante um determinado período de tempo (estágio um).

Os casais que concluem o estudo mais rápido do que os outros podem receber perguntas adicionais, o que é recomendado em muitas atividades de treinamento colaborativo. Em seguida, os pares trocam de papéis e repetem a entrevista (estágio dois). Em seguida, os alunos formam um grupo de quatro e colaboram com os membros do grupo, não com suas próprias perspectivas dos atribuídos,

Essa estrutura reforça as habilidades de ouvir e testar; Ajuda os alunos a processar e ensaiar informações e resultados no desenvolvimento de ideias compartilhadas. Os professores desejam que os alunos se preparem para esta aplicação; Para fazer a si mesmo perguntas na entrevista, é necessário entender os conceitos importantes desta seção, ela pode ser incentivada fazendo um anúncio. As perguntas baseadas no conteúdo, quando usadas no início da lição, fornecem aos alunos um feedback imediato sobre sua compreensão do material do curso designado. 
Não importa o quão cuidadosamente os professores planejem, as coisas podem dar errado. No entanto, correr riscos é necessário para o desenvolvimento profissional. O importante é não desistir. No entanto, os blogs e páginas da web disponíveis para os membros do corpo docente podem consultar ou observar colegas com conhecimento ou especialistas em treinamento de professores e expressar suas experiências em seus sites pessoais, sendo essas experiências ricas e estranhas para serem levadas para nossa sala de aula como uma opção de aprendizagem, já que os docentes podem participar de oficinas de treinamento que demonstram técnicas e atividades de gestão de sala de aula, como o documento de dupla entrada, solução estruturada de problemas, pensamento e compartilhamento, o questionário visível, a mesa redonda e a entrevista em três etapas.

\section{Conclusões}

Os membros de qualquer corpo docente ou escola que entendam a teoria e pesquisa subjacentes ao aprendizado ou treinamento colaborativo, e as técnicas de gerenciamento de sala de aula que garantirão sua implementação tranquila, serão capazes de adaptar esta prática a qualquer currículo. Como resultado, o aprendizado pode se aprofundar; os alunos podem gostar de assistir às aulas e podem respeitar e valorizar as contribuições de seus colegas.

Millis (2000-2001) explica que a formação colaborativa não é uma tendência que rapidamente saia de moda: onde nos ajudará a manter o foco no aluno sem tirar a responsabilidade de moldar uma sala de aula com base em nossa experiência e conhecimento. Fornecendo ferramentas para criar atividades que maximizam o aprendizado. Isso não apenas nos ajuda a melhorar o aprendizado, mas também nos ajuda a colher outros benefícios positivos, como aumento da autoestima, respeito pelos outros e cortesia.

O treinamento colaborativo pode transformar nossas salas de aula lotadas e diversificadas em equipes que se apoiam mutuamente. Este tipo de treinamento colaborativo satisfaz o desejo humano dos alunos de vínculo e colaboração. Além disso, mantém os alunos com energia e alerta e fornece suporte social para lidar com tarefas complexas que não podem ser realizadas sozinho. Ele fornece aos alunos as habilidades sociais e de comunicação necessárias em sua vida pessoal, de treinamento e de negócios. 


\section{Referências}

Angelo, TA e Cross, KP (1993). Técnicas de avaliação em sala de aula: um manual para professores universitários. $2^{\mathrm{a}}$ Ed. São Francisco: Jossey - Bass.

Belenky, MF, Clinchy, BM, Goldberger, NR e Tarule, JM (1986). Formas de conhecimento das mulheres: O desenvolvimento de si, da voz e da mente. Nova York: Basic Books.

Bransford, JD, Brown, AL e Cocking, RR (Eds.). (2000). Como as pessoas aprendem: cérebro, mente, experiência e escola. Comissão de Ciências Sociais e Comportamentais e do Conselho Nacional de Pesquisa em Educação. Washington, DC: National Academy Press.

Brookfield, SD (1987). Desenvolva pensadores críticos: desafie os adultos a explorar maneiras alternativas de pensar e agir. São Francisco.

Chickering, AW e Gamson, AF (1987). Sete princípios de boas práticas no ensino de graduação. Racine, WI: The Johnson Foundation.

Cooper, J. e Mueck, R. (1990). Participação do Aluno na Aprendizagem: Aprendizagem Cooperativa e Instrução Universitária. Revista de excelência no ensino universitário.

Felder, RM e Brent, R. (1994). Aprendizagem cooperativa em cursos técnicos: procedimentos, armadilhas e recompensas. 22 de setembro de 2002.

Jensen, E. (2000). Aprendizagem baseada no cérebro. Ed revisado. San Diego: The Brain Store.

Johnson, DW, Johnson, RT e Smith, KA (1991). Aprendizagem cooperativa: aumentando a produtividade educacional do corpo docente universitário. (Relatório ASHE-ERIC Ensino Superior No.4). Washington, DC: Escola de Educação e Desenvolvimento Humano da George Washington University.

Johnston, S. e Cooper, J. (1997). Pensamentos rápidos: Tarefas de pensamento ativo em palestras e instruções na televisão. Aprendizagem cooperativa e ensino universitário. Água parada.

Kagan, S. (1989). Recursos de aprendizagem cooperativa para professores. San Capistro, CA: Teacher Resources, Inc.

Leamnson, R. (1999). Pensando no ensino e na aprendizagem: desenvolvendo hábitos de aprendizagem com alunos do primeiro ano de faculdade e universitários. Sterling, VA: Stylus Press.

Millis, B. (2000-2001). Aprendizagem cooperativa: veio para ficar. Excelência de ensino: em direção ao melhor da academia. A Rede de Desenvolvimento Profissional e Organizacional no Ensino Superior.

Millis, B. e Cottell, P. (1998). Aprendizagem cooperativa para professores do ensino superior. American Council of Education Press.

Myers, C. e Jones, TB (1993). Promoting Active Learning: Strategies for the University of San Francisco.

Palmer, PJ (1996). Renovação da comunidade no ensino superior em We Campbell \& KA Smith, New Paradigms for College Teaching Interaction Book Company.

Rhem, J. (1995). Primeiro plano: aprofundamento. O Fórum Nacional de Ensino e Aprendizagem. 
Sapon-Shevin, M., Ayres, BJ e Duncan, J. (1994). Aprendizagem cooperativa e inclusão. De JS Thousand, RA Villa e AI Nevin, Criatividade e Aprendizagem Colaborativa: Um Guia Prático para Capacitar Alunos e Professores. Baltimore: Paul H. Brookes Publishing Co.

Slavin, RE (1989-1990). Pesquisa em aprendizagem cooperativa: consenso e controvérsia Liderança educacional.

Staley, C. (2003). Cinquenta maneiras de sair do púlpito. Wadsworth / Thompson.

Stein, RF e Hurd, S. (2000). Usando equipes de alunos na sala de aula: um guia para professores. Bolton, MA: Anker Publishing Company.

Tang, C. (1998). Efeitos da aprendizagem colaborativa na qualidade das tarefas. Em B. Dardos e G. Bolton-Lewis, Ensino e aprendizagem no ensino superior. Melbourne, Austrália.

Tuckman, B. (1965). Sequência de desenvolvimento de pequenos grupos. Boletim psicológico.

Tuckman, B. e Jensen, MAC (1977). Os estágios de desenvolvimento de pequenos grupos foram revisados. Estudos de grupo e organizacionais. 